\title{
Immunoglobulin Kappa Chain Receptor Editing in Systemic Lupus Erythematosus
}

Thomas Dörner, Sandra J. Foster, Nancy L. Farner, and Peter E. Lipsky

Department of Internal Medicine and Harold C. Simmons Arthritis Research Center, University of Texas Southwestern Medical Center at

Dallas, Dallas, Texas 75235

\begin{abstract}
To determine whether receptor editing of Vк genes was involved in the pathogenesis of systemic lupus erythematosus (SLE), the usage of $\mathrm{V} \kappa$ and $\mathrm{J}_{\kappa}$ gene elements from individual peripheral $\mathrm{CD}^{+}{ }^{+} \mathrm{B}$ cells obtained from a patient with untreated SLE was examined. No differences in the $V \kappa$ and $\mathrm{J}_{\kappa}$ gene usage in the nonproductive gene repertoire of this SLE patient were noted compared with the distribution of genes found in normal adults. However, an increased usage of $\mathrm{J} \kappa 5$ segments, and a significant overrepresentation of the $\mathrm{V} \kappa 1$ and $V_{\kappa} 4$ families, especially the L15, O14/O4, and B3 genes characterized the productive $V \kappa$ gene repertoire of the SLE patient. Furthermore, $\mathrm{J}_{\kappa 5}$-containing Vк gene rearrangements in the productive but not the nonproductive repertoire manifested significantly fewer mutations compared with $V_{\kappa}$ genes recombined with $J_{\kappa} 1-4$. These data are consistent with the conclusion that receptor editing of $\mathrm{V \kappa}$ is much more apparent in this SLE patient than in normals and suggest that a deficiency in this means to counteract the emergence of autoimmunity is not an essential feature of SLE. (J. Clin. Invest. 1998. 102:688-694.) Key words: Vк rearrangements • SLE • autoimmune diseases - receptor editing • B lymphocytes • generation of diversity
\end{abstract}

\section{Introduction}

Systemic lupus erythematosus (SLE) is the prototype of a systemic autoimmune disease characterized by B cell hyperreactivity and the production of a variety of autoantibodies (1). Although knowledge about the autoantibodies produced by SLE patients and their cognate autoantigens is increasing, the molecular basis of the induction of autoimmunity remains enigmatic. The potential roles of molecular processes and subsequent selective influences in the generation of autoreactive B cells in SLE have not been fully delineated. Immunoglobulin genes are assembled during early B cell development by the recombination of variable (V), diversity (D) and joining $(\mathrm{J})$ elements in the bone marrow by a lymphocyte specific

Address correspondence to Dr. Peter E. Lipsky, Department of Internal Medicine, Harold C. Simmons Arthritis Research Center, University of Texas Southwestern Medical Center at Dallas, 5323 Harry Hines Blvd., Dallas, TX 75235-8884. Phone: 214-648-9110; FAX: 214648-7995; E-mail: peter.lipsky@email.swmed.edu

Received for publication 15 February 1998 and accepted in revised form 17 June 1998.

J. Clin. Invest.

(C) The American Society for Clinical Investigation, Inc. 0021-9738/98/08/0688/07 \$2.00

Volume 102, Number 4, August 1998, 688-694

http://www.jci.org
$\mathrm{V}(\mathrm{D}) \mathbf{J}^{1}$ recombinase $(2,3)$. In the bone marrow, expression of one membrane-bound B cell receptor (BCR) extinguishes subsequent rearrangements by downregulation of the expression of recombination activating genes (RAG) 1 and RAG2 (4). However, some immature $\mathrm{B}$ cells expressing self-reactive BCRs retain or reexpress sufficient RAG activity to replace those autoreactive receptors by continued Ig gene recombination (receptor editing) and thereby survive negative selection $(5,6)$. In the periphery, exposure to exogenous antigen can stimulate somatic hypermutation and also reexpression of RAG1 and RAG2 in germinal centers (7-9). If the mutational process generates an autoreactive $\mathrm{BCR}$, additional receptor editing in the secondary lymphoid organs could potentially replace the autoreactive BCR and permit the survival of the B cell.

The possibility that deficiencies in central or peripheral receptor editing could play a role in generating autoimmunity has been suggested (10-14), but only a small number of studies have examined this hypothesis directly. Thus, Bensimon et al. (15) analyzed clones obtained from SLE patients and noted an overusage of $\mathrm{J}_{\kappa}$ proximal $\mathrm{V} \kappa 1$ genes and preferential use of $\mathrm{J}_{\kappa}$ elements proximal to $V_{\kappa}$ and suggested that receptor editing in SLE might be defective. In addition, a lack of receptor editing of $V_{\kappa}$ rearrangements using the $V_{\kappa}$ gene, A30, and $J_{\kappa} 2$ and encoding anti-dsDNA antibodies has been suggested to occur in patients with SLE and nephritis (13). These conclusions, however, are only inferential, and little direct evidence of defects in receptor editing in SLE patients has been provided. Moreover, the use of $\mathrm{J}_{\kappa}$ distal Vк genes in some autoantibodies of SLE patients $(16,17)$ has suggested that receptor editing might be intact in these patients. Therefore, it is not clear whether receptor editing is intact or defective in SLE patients.

In the current study, we tested the hypothesis that receptor editing is defective in SLE patients by profiling the distribution of $V \kappa$ and $\mathrm{J}_{\kappa}$ gene elements in individual B cells of a patient with early, untreated SLE. Evidence of $\kappa$ chain gene receptor editing was sought by comparing the distribution of $V_{\kappa}$ and $J_{\kappa}$ gene usage with that of normal donors (18). The data provide clear evidence that receptor editing was intact in this SLE patient and more apparent than that found in normals. The data therefore challenge the hypothesis that receptor editing is uniformly defective in patients with SLE.

\section{Methods}

Patient material. B cells were obtained from a 54-year-old Hispanic man with SLE, which was previously undiagnosed. Of note, his sister had SLE for 12 years. The primary care physician treated the patient with hydroxychloroquine for $8 \mathrm{~d}$ because of evolving subacute cutaneous lupus erythematosus (SCLE)-like lesions in sun-exposed areas, but no other therapy had been administered. Additional clinical

1. Abbreviations used in this paper: $\mathrm{BCR}, \mathrm{B}$ cell receptor; RAG, recombination activating gene; SCLE, subacute cutaneous lupus erythematosus; $\mathrm{V}(\mathrm{D}) \mathrm{J}$, variable, diversity and joining. 
symptoms were increased fatigue, intermittent episodes of fever, malar rash and arthralgias of the proximal interphalangeal joints. Physical examination showed a typical butterfly rash and hyperkeratotic lesions of SCLE. Mild proteinuria was evident with $300-500 \mathrm{mg}$ of protein per day. Serologically, the ANA titer was 1:2,560 (speckled pattern), with antibodies to Ro, La, and RNP present. Anti-dsDNA antibodies were not present. White blood cell count was $3.8 \times 10^{3} / \mu \mathrm{l}$ with $20 \%$ lymphocytes. Complement factors C3 $(62.6 \mathrm{mg} / \mathrm{dl}$; normal: 65-203) and C4 (<10 mg/dl; normal: 16-54) were reduced. Taken together, the patient fulfilled the revised criteria for classification of SLE (19).

Preparation of PBMC. PBMC were prepared from $50 \mathrm{ml}$ of anticoagulated peripheral blood by centrifugation over ficoll hypaque gradients. Thereafter, $10 \times 10^{6}$ PBMC were stained using FITClabeled anti-human CD19 (Sigma Chemical Co., St. Louis, MO) according to a previously described protocol (20).

FACS sorting and PCR amplification. 276 individual CD19+ $\mathrm{B}$ cells were sorted into wells of 96-well plates (Robbins Scientific, Sunnyvale, CA) by using a FACS ${ }^{\circledR}$ Star Plus flow cytometer with an automated single-cell deposit unit (Becton Dickinson, San Jose, CA), as described previously $(20,21) .12$ wells (4 per plate) that received no cells served as negative controls. Rearranged $V_{\kappa} \mathrm{J}_{\kappa}$ genes were then amplified as described (18). The PCR amplification included a primer extension preamplication (20) and subsequent nested PCR steps (18). After column purification of PCR products (GenElute Agarose Spin Column; Supelco, Bellefonte, PA), all PCR products were directly sequenced using the ABI Prism Dye Termination Cycle Sequencing Kit (Applied Biosystems, Inc., Foster City, CA) and analyzed with an automated Sequencer (ABI Prism 377; Applied Biosystems, Inc.). Sequences were analyzed using the V BASE Sequence Directory (22) to identify the respective germline gene. For the identification of the underlying germline segments, the software programs GeneWorks (release 2.45; IntelliGenetics Inc., Mountain View, CA) and Sequencher (Gene Codes Corp., Ann Arbor, MI) were used.

$\mathrm{V \kappa}_{\kappa} \mathrm{J}_{\kappa}$ rearrangements from two healthy normal male donors (26 years old and 45 years old) that had been published previously (18) were used for comparison. Both the nonproductive and productive repertoires of these two normal, age disparate donors exhibited a comparable usage of $\mathrm{V} \kappa$ and $\mathrm{J}_{\kappa}$ gene elements.

The methodology used made it possible to amplify Ig gene rearrangements from peripheral B cells and, thereby, avoid biases inherent in analyzing cell lines or cDNA libraries $(18,21)$. Since genomic DNA was amplified, productive as well as nonproductive $V_{\kappa}$ rearrangements could be amplified, sequenced, and analyzed. Analysis of the nonproductive repertoire is especially important in assessing the immediate product of the $\mathrm{V}(\mathrm{D}) \mathrm{J}$ rearrangement process or the impact of somatic hypermutation, as the nonproductive rearrangements do not encode a protein and therefore do not influence selection of B cells expressing these rearrangements. In contrast, the distribution of B cells can be influenced by a variety of selective influences during development and subsequent antigenic stimulation based upon the nature of the expressed $\mu$ or $\kappa$ chain. Moreover and critical for this analysis, the presence of $B$ cells rescued from deletion by receptor editing should influence the distribution of $\mathrm{V}_{\kappa}$ and $\mathrm{J}_{\kappa}$ genes in the productive but not in the nonproductive repertoires. The critical assumption of this analysis is that the distribution of nonproductive rearrangements reflects the same recombination biases as that governing the productive rearrangements. The results supporting this contention have been presented previously $(18,20,21,23-25)$.

Determination of Taq polymerase fidelity and the frequency of potential sequence errors. The maximal PCR error rate for this analysis has been documented to be $1.2 \times 10^{-3}$ mutations per base pair or $\sim 0.3$ errors per $\mathrm{VK}_{\mathrm{K}} \mathrm{K}$ rearrangements (23). Further analysis of the error rate of the single-cell PCR indicated that when a known Ig sequence of 238 bp was subjected to the preamplification and subsequent nested amplification procedures, 2 sequence errors were detected in 81 resulting copies (19,261 bp). Thus, few of the nucleotide changes encountered in this analysis can be ascribed to amplification errors.
Statistical analysis. Sequences were analyzed with the chi-square test to compare the differences in the distribution of particular gene segments as well as mutational frequencies between the $V_{\kappa}$ rearrangements of the SLE patient and the normals. The goodness of fit $\chi^{2}$ test (26) was used to compare the actual distribution of $V_{\kappa}$ and $\mathrm{J}_{\kappa}$ family gene usage in the SLE patient with the frequency that might be expected based upon the number of genes in the genome (18). The $\chi^{2}$ test was used to compare the usage of $V_{\kappa}$ and $J_{\kappa}$ elements in the SLE patient and normals. Where indicated, the Bonferroni correction was applied to consider the influence of multiple variables (26). $P$ values $<0.05$ were considered to be statistically significant.

\section{Results}

$76 \mathrm{V \kappa J}_{\kappa}$ gene rearrangements were obtained from the 276 sorted individual B cells (accession numbers EMBL Data Bank AJ223638-AJ223713). These included a total of 59 productive and 17 nonproductive $V_{\kappa}$ rearrangements. The nonproductive $V_{\kappa}$ rearrangements failed to maintain the reading frame into the $\mathbf{J}$ segment. Most wells had a single $V_{\kappa}$ rearrangement per well (56 out of 76, 73.7\%). These included 44 productive and 12 nonproductive $V_{\kappa}$ rearrangements. In five cases, two productive $(8.9 \%)$ rearrangements and in five cases, one productive and one nonproductive $(8.9 \%)$ rearrangement per well were detected. No well contained more than two $V_{\kappa}$ rearrangements.

$V \kappa$ gene usage in SLE. The distribution of the usage of particular $V_{\kappa}$ families is shown in Fig. 1. Members of the $V_{\kappa} 7$ family were found neither in the SLE nor in the normal reper-

\section{Nonproductive}
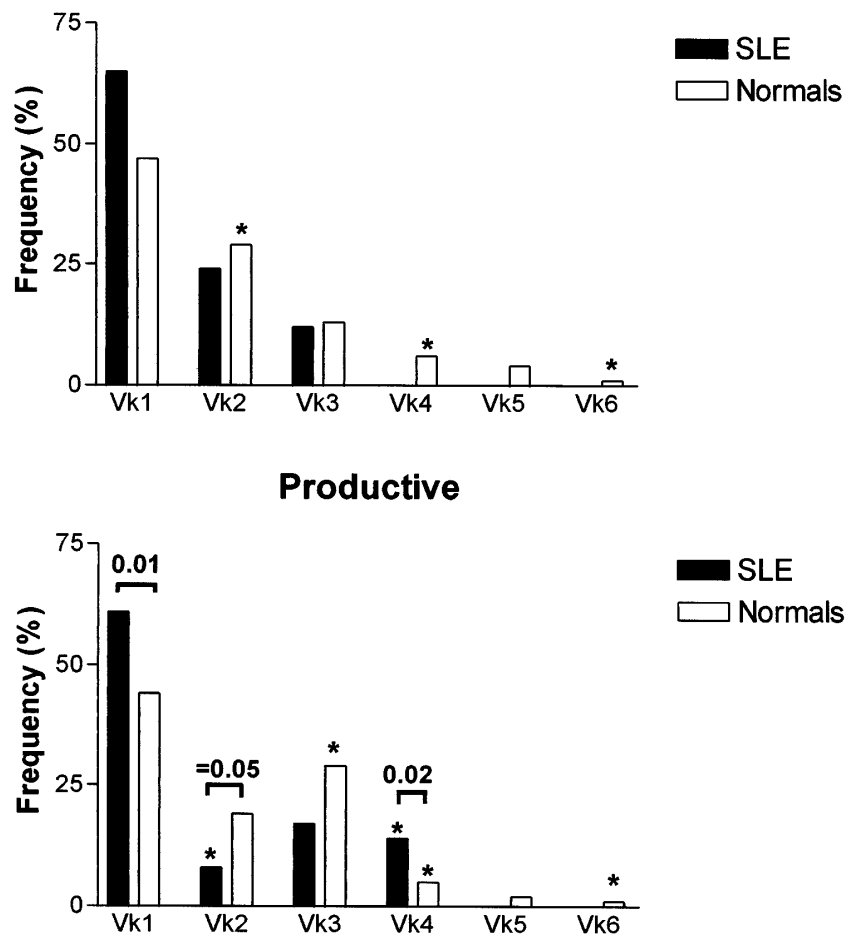

Figure 1. Distribution of Vк families in an SLE patient compared with normals. $(*, P<0.01$, significantly different than predicted from its presence in the genome; goodness of fit $\chi^{2}$ test). Brackets indicate significant differences between $V \kappa$ usage in the productive repertoire of normals and the SLE patient ( $\chi^{2}$ test). 
toire, whereas $V_{\kappa} 5$ and $V_{\kappa} 6$ genes were not detected in SLE. It should be noted that the usage of $V_{\kappa} 1$ and $V_{\kappa} 4$ family members was significantly more frequent in the productive repertoire of the SLE patient compared with the normals $(P<0.01$ and $P<0.02$, respectively, $\chi^{2}$ test). Although $\mathrm{V} \kappa 2_{2}$ and $\mathrm{V} \kappa 3_{3}$ families were used less often in the productive SLE repertoire, the differences in frequencies of these families compared with the normals were of borderline significance ( $\mathrm{V}_{\kappa} 2 P=0.05$, $\left.V_{\kappa} 3 P=0.05\right)$. However, when the usage of particular $V_{\kappa}$ families in the SLE patient was compared with the expected frequency based on random usage, the $V_{\kappa} 2$ family was found to be significantly underrepresented in the SLE patient $(8 \%$ compared with the expected $22.5 \% ; P<0.01$ ). Moreover, as suggested above, the VК4 family, with the single gene, B3, occurred significantly more often than expected by random chance ( $14 \%$ vs. $2.5 \% ; P<0.001$, goodness of fit $\chi^{2}$ test). By this analysis, no significant differences were noted for the nonproductive rearrangements of the SLE patient, although the overrepresentation of $V_{\kappa} 1$ genes $(65 \%)$ suggests a molecular preference to rearrange these genes in SLE.

Distribution of individual $V \kappa$ genes in $B$ cells from SLE. As shown in Fig. 2, the distribution of individual $V_{\kappa}$ genes in

\section{A}

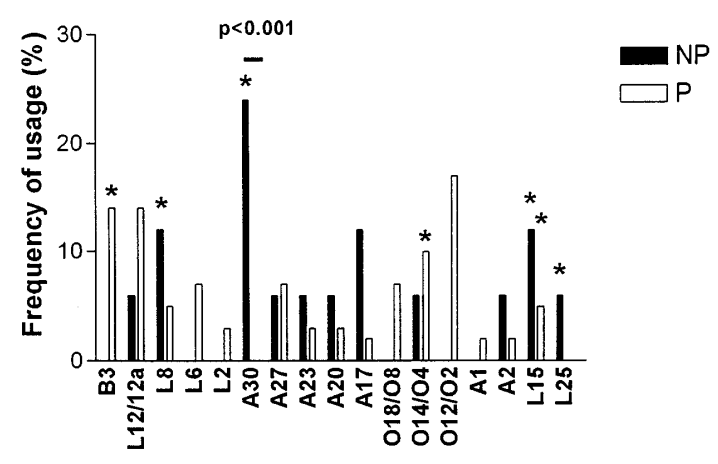

B

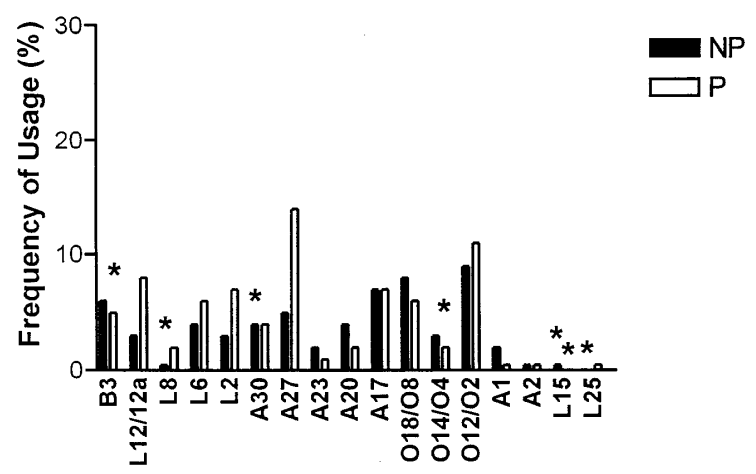

Figure 2. Distribution of individual $\mathrm{V}_{\kappa}$ gene segments in SLE $(A)$ and normal adults $(B ; 18)$. $\mathrm{J} \kappa$ proximal to $\mathrm{J} \kappa$ distal $\mathrm{V} \kappa$ genes are shown in order from left to right. *Indicates significantly $(P<0.001)$ more frequent in the nonproductive repertoire in the SLE patient when compared with the usage of these particular genes in normals (L8, A30, L15, and L25, $\chi^{2}$ test) and in the productive repertoire in the SLE patient when compared with the usage of these particular genes in normals $(P<0.001$ for $\mathrm{L} 15$ and $\mathrm{O} 14 / \mathrm{O} 4, P<0.02$ for B3). the SLE patient and in the normal donors showed some differences in the productive and nonproductive repertoires. When the usage of particular $V_{\kappa}$ gene segments by the SLE patient was compared with the normals, B3 (14\%; $P<0.02), 014 / \mathrm{O} 4$ (10\%; $P<0.001)$, and L15 (5\%; $P<0.001, \chi^{2}$ test) were found to be significantly overrepresented in the productive SLE repertoire. In the nonproductive repertoire of the patient, A30 (24\%; $P<0.001)$, L8 (12\%; $P<0.001)$, L15 (12\%; $P<0.001)$, and L25 $(6 \% ; P<0.001)$ were significantly more frequent than in normals. The occurrence of some infrequently used $\mathrm{V}_{\mathrm{K}}$ genes (B2, L11, L10, L9, L5, L4, L2, L1, A26, A23, A21, A19, A18, O11/O1, A4, A7, A11, L19, L20, L23, and L24) in the normal donors (18) was not significantly different than that found in the SLE patient. The significant overrepresentation of the Vк1 family gene, L15, in both the productive and nonproductive SLE repertoire is noteworthy. Finally, the Vк1 family member, A30, was significantly overrepresented in the nonproductive rearrangements of this SLE patient $(P<0.001$, $\chi^{2}$ test) and exclusively rearranged with $\mathrm{J}_{\kappa} 2$. Similar differences between the distribution of this $V_{\kappa}$ gene in productive and nonproductive repertoires were also found in normals (data not shown).

Comparison of the usage of the $J_{\kappa}$ proximal and $J \kappa$ distal cassette. Because of a gene duplication event during phylogeny, the $V_{\kappa}$ locus is composed of two cassettes of genes (27). The $\mathrm{J}_{\kappa}$ proximal cassette is orientated so that most rearrangements occur by deletion, whereas the $\mathrm{J} \kappa$ distal cassette is arranged in the opposite orientation and recombination proceeds by inversion. Based upon the assumption that receptor editing might lead to greater usage of $V_{\kappa}$ genes from the $J_{\kappa}$ distal cassette, the frequency of these genes in the productive repertoire of the SLE patient was examined and compared with their presence in the nonproductive rearrangements. In the nonproductive repertoire of the SLE patient, 12 out of 17 $\mathrm{V} \kappa(70.6 \%)$ genes belonged to the $\mathrm{J}_{\kappa}$ proximal cassette, and 3 out of $17(17.6 \%)$ were from the $\mathrm{J}_{\kappa}$ distal cassette. Two Vк genes $(11.8 \%$; L25 or L10 and O14 or O4) could not be ascribed to either of these regions. In the productive repertoire, 34 out of $59(57.6 \%)$ Vk genes were part of the proximal, whereas 5 out of $59(8.5 \%) \mathrm{V} \kappa$ elements were part of the $\mathrm{J}_{\kappa}$ distal cassette. In this group of rearrangements, 20 genes (33.9\%; O18 or O8, O14 or O4, and O12 or O2) could not be definitively assigned. Despite the comparable use of the JK distal cassette of $V_{\kappa}$ genes by productive and nonproductive rearrangements, further analysis indicated that the productive repertoire of the SLE patient was indeed biased toward the use of $\mathrm{J}_{\kappa}$ distal $\mathrm{V} \kappa$ genes. This was noted, when $\mathrm{V} \kappa$ genes were divided into A17 proximal and A17 distal gene groups (A17 is $\sim 380 \mathrm{kB}$ distal from $\left.\mathrm{J}_{\kappa} 1\right)$. There was no significant difference in the usage of $\mathrm{A} 17$ distal $\mathrm{V}_{\kappa}$ genes in the nonproductive repertoire of the SLE patient and normals $(29.4 \%$ vs. $23.2 \%, P=$ 0.56). However, the difference in the usage of A17 distal $V_{\kappa}$ genes in the productive repertoire of the SLE patient $(42.3 \%)$ compared with that found in the normals (19.6\%) was highly significant $\left(P<0.001, \chi^{2}\right.$ test $)$. Despite the preferential usage of the $\mathrm{J}_{\kappa}$ distal $\mathrm{V \kappa}$ genes, the most Јк proximal gene, the single $\mathrm{V} \kappa 4$ family member, B3, was also overrepresented in the productive repertoire of the SLE patient compared to the normals $(14 \%$ vs. $5 \%, P<0.02)$.

$J \kappa$ gene usage in SLE. The distribution of the rearranged $\mathrm{J}_{\kappa}$ elements in the SLE patient is shown in Table I. Most notably, the usage of the $V_{\kappa}$ distal $\mathrm{J}_{\kappa} 5$ segment was significantly in- 
Table I. Distribution of $J_{\kappa}$ Gene Usage in SLE

\begin{tabular}{|c|c|c|c|c|c|c|c|c|}
\hline & \multicolumn{4}{|c|}{ SLE } & \multicolumn{4}{|c|}{ Normals } \\
\hline & \multicolumn{2}{|c|}{ Nonproductive } & \multicolumn{2}{|c|}{ Productive } & \multicolumn{2}{|c|}{ Nonproductive } & \multicolumn{2}{|c|}{ Productive } \\
\hline & $n$ & $\%$ & $n^{*}$ & $\%$ & $n$ & $\%$ & $n$ & $\%$ \\
\hline Јк1 & 3 & 18 & 14 & 24 & 50 & 21 & 97 & 30 \\
\hline $\mathrm{J}_{\kappa} 2$ & $9^{\ddagger}$ & 53 & 19 & 32 & 92 & 40 & 115 & 36 \\
\hline $\mathrm{J}_{\kappa} 3$ & 2 & 12 & $3^{\ddagger}$ & 5 & 9 & 4 & 18 & 6 \\
\hline $\mathrm{J}_{\kappa} 4$ & 1 & 6 & $1^{\ddagger \S}$ & 2 & 46 & 20 & $56^{\S}$ & 17 \\
\hline $\mathrm{J}_{\kappa} 5$ & 2 & 12 & 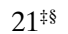 & 36 & 35 & 15 & $35^{\S}$ & 11 \\
\hline
\end{tabular}

*One $\mathrm{J}_{\kappa}$ gene productively rearranged with $\mathrm{V}_{\kappa} \mathrm{O} 12 / \mathrm{O} 2$ could not be ascribed as a specific segment and therefore was not considered in this analysis. ${ }^{\ddagger} P<0.005$, significantly different than the number expected by random chance ( $\chi^{2}$ goodness of fit test with Bonferroni correction). ${ }^{\S}$ Significant difference between the usage of $\mathrm{J}_{\kappa} 4(P<0.002)$ and $\mathrm{J}_{\kappa} 5(P<$ $0.001)$ genes, respectively, in the productive SLE repertoire compared with normals $\left(\chi^{2}\right)$.

creased in the productive rearrangements of the SLE patient, with $36 \%$ of $\mathrm{V \kappa J}_{\kappa}$ rearrangements using this element. In contrast, only $12 \%$ of the nonproductive rearrangements used this Jк element $\left(P<0.005, \chi^{2}\right.$ goodness test with Bonferroni correction). Furthermore, the usage of $\mathrm{J}_{\kappa} 3(P<0.005)$ and $\mathrm{J}_{\kappa} 4(P<$ $0.005)$ was significantly less frequent in the productive SLE repertoire than expected by chance alone. Overuse of $\mathrm{J}_{\kappa} 5$ in the productive repertoire of the SLE patient was confirmed by comparison with the normal donors. A significantly greater usage of $\mathrm{J}_{\kappa} 5$ in the productive $\mathrm{V}_{\kappa} \mathrm{J}_{\kappa}$ rearrangements of the SLE patient was observed ( $36 \%$ vs. $11 \% ; P<0.001, \chi^{2}$ test), whereas $\mathrm{J}_{\kappa} 4$ was used significantly less in the productive SLE repertoire $(2 \%$ vs. $17 \% ; P<0.001)$. Comparison of the usage of the remaining $\mathrm{J}_{\kappa}$ elements revealed no significant differences between the SLE patient and normals.

Mutational analysis between $J \kappa 5$ - and $J \kappa 1-4-u$ sing $V k$ rearrangements. Productive $\mathrm{J}_{\kappa} 5$-using rearrangements from the SLE patient were found to use B3 and the A17 distal Vk elements O12/O2, O14/O4, and O18/O8 predominantly (Fig. 3). Moreover, the frequencies of mutations of the VK rearrangements using $\mathrm{J}_{\kappa} 5$ on the one hand or $\mathrm{J}_{\kappa} 1-4$ on the other were significantly different (Table II). Thus, productively rearranged $V \kappa$ genes using $\mathrm{J}_{\kappa} 5$ contained significantly fewer mutations (frequency 1.99\%; 99 mutations per 4,979 bp) than Јк14-using Vк rearrangements (frequency: 3.08\%; 280 mutations per 9,077 bp, $P<0.001, \chi^{2}$ test). Similarly, when the A17 distal $\mathrm{V} \kappa$ genes $(\mathrm{O} 12 / \mathrm{O} 2, \mathrm{O} 14 / \mathrm{O} 4$, and $\mathrm{O} 18 / \mathrm{O} 8)$ and the $\mathrm{B} 3$ gene were analyzed for their mutational frequencies, JK1-4-containing $\mathrm{V \kappa}$ rearrangements were mutated significantly more (frequency $3.1 \%$; 79 mutations per 2,506 total bp) than the rearrangements using $\mathrm{J}_{\kappa} 5$ genes (frequency $1.6 \% ; 69$ mutations per $4,275 \mathrm{bp} ; P<0.001)$. Of importance, Jк5-using gene rearrangements manifested a high frequency of mutations in the nonproductive repertoire, indicating that $\mathrm{V}_{\kappa} / \mathrm{J}_{\kappa} 5$ rearrangements could be subjected to mutations.

\section{Discussion}

The results of the current study suggest that peripheral B cells of this SLE patient receptor edit at the VK locus more actively than previously noted in normals. This was manifested by devi-
Nonproductive

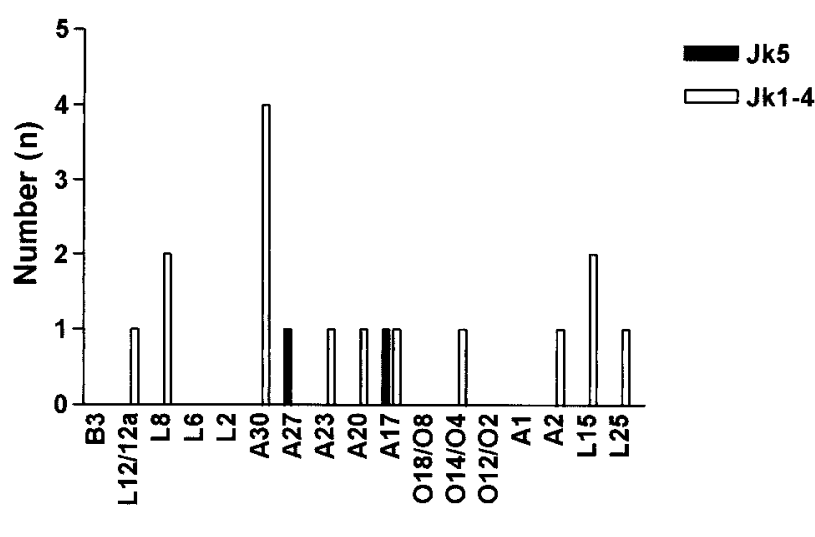

Productive

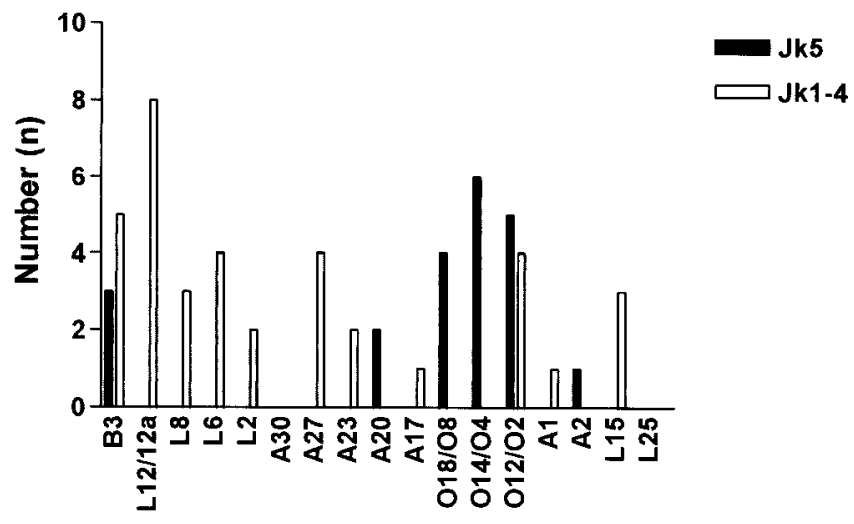

Figure 3. Distribution of specific Vк genes by $\mathrm{J}_{\kappa} 5$ - and $\mathrm{J}_{\kappa} 1-4-\mathrm{using}$ rearrangements in an SLE patient. The Vк elements appear in the order in which they appear in the genome from B3 (most Jк proximal

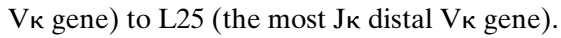

ation in the distribution of both $\mathrm{V} \kappa$ and $\mathrm{J} \kappa$ elements in the productive but not in the nonproductive repertoire, so that the frequencies of both the $\mathrm{J}_{\kappa}$ distal $\mathrm{V} \kappa$ elements and the $\mathrm{V}_{\kappa}$ distal $\mathrm{J}_{\kappa}$ segment were increased. That receptor editing leading to these deviations occurred in secondary lymphoid organs after the mutational process had been initiated is indicated by the significantly lower mutational frequencies of rearrangements using these gene elements. These results imply that rather than being defective, peripheral receptor editing is markedly active in this patient with SLE. The capacity to bind autoantigens has been shown to emerge during immune responses to conventional exogenous antigens by somatic hypermutation of $\mathrm{Ig}$ genes with no intrinsic autoantibody activity (28-32). Moreover, somatic hypermutation of Ig genes with autoantibody specificity can increase the avidity of autoantigen binding (3335 ). Either process could provide the impetus for receptor editing in secondary lymphoid organs after initiation of somatic hypermutation. Alternatively, increased receptor editing may have been induced in this SLE patient to replace Ig genes that became defective in antigen binding or expression as a result of somatic hypermutation $(23,24)$.

Although Ig heavy chains $(34,36)$ have been shown to contribute to autoantigen binding, the important influence of light chains for autoantigen binding has been repeatedly emphasized $(13,16,17,35)$. Thus, the current evidence of receptor 
Table II. Comparison of the Mutational Frequencies between $V \kappa$ Gene Rearrangements That Use $J_{\kappa} 5$ and Those Using $J_{\kappa} 1-4$

\begin{tabular}{|c|c|c|c|c|c|c|}
\hline \multirow[b]{2}{*}{ Rearrangements } & \multicolumn{3}{|c|}{ Nonproductive } & \multicolumn{3}{|c|}{ Productive } \\
\hline & $\begin{array}{l}\text { Mutations } \\
\text { (n) }\end{array}$ & $\begin{array}{c}\text { Total } \\
\text { bp }\end{array}$ & $\begin{array}{c}\text { Mutational } \\
\text { Frequency } \\
(\%)\end{array}$ & $\begin{array}{l}\text { Mutations } \\
\text { (n) }\end{array}$ & $\begin{array}{c}\text { Total } \\
\text { bp }\end{array}$ & $\begin{array}{c}\text { Mutational } \\
\text { Frequency } \\
\quad(\%)\end{array}$ \\
\hline $\mathrm{J} \kappa 1-4$ & 109 & 3655 & $2.98 *$ & 280 & 9077 & $3.08^{*}$ \\
\hline $\mathrm{J} \kappa 5$ & 37 & 399 & $9.27 * \frac{\ddagger}{\ddagger}$ & 99 & 4979 & $1.99 * \ddagger$ \\
\hline Total & 146 & 4054 & $3.60^{\ddagger}$ & 379 & 14056 & $2.70^{\ddagger}$ \\
\hline
\end{tabular}

${ }^{*} P<0.001$, significant difference in the mutational frequency between $\mathrm{J}_{\kappa} 1-4$ and $\mathrm{J}_{\kappa} 5$ using rearrangements in the productive and nonproductive repertoire $\left(\chi^{2}\right.$ test). ${ }^{\ddagger} P<0.002$, significant difference between the mutational frequency of productive and nonproductive $V_{\kappa}$ rearrangements $\left(\chi^{2}\right.$ test $)$

editing of kappa light chains implies that this process in SLE patients might be driven by the emergence of autoantibodies or increased avidity of autoantigen binding from the activation of the mutational process in secondary lymphoid organs.

Of note, the distribution of $\mathrm{V} \kappa$ gene family usage found in the nonproductive repertoire of the SLE patient, although limited, was similar to that found in normals. Furthermore, usage of $\mathrm{J}_{\kappa}$ elements in the nonproductive SLE repertoire was also similar to that found in the normals. This suggests that there are no apparent differences in molecular processes that generate the Vк gene repertoire in this patient compared with that involved in the normal adult repertoire. Importantly, a molecular preference to rearrange $\mathrm{J}_{\kappa} 5$ in SLE was not found, implying that the increased use of $\mathrm{J}_{\kappa} 5$ in the productive rearrangements of the SLE patient related to events that occurred after $V_{\kappa} \mathrm{J}_{\kappa}$ rearrangement and requiring expression of a $\kappa$ chain protein. This bias could relate to a form of positive selection not observed in normals. Alternatively, and more likely because of the $V_{\kappa}$ distal location of $\mathrm{J}_{\kappa 5}$, the diminished frequency of mutations in $\mathrm{J}_{\kappa} 5$ containing rearrangements and the discrepancy in this finding between normals and the SLE patient, the overrepresentation of $\mathrm{J}_{\kappa} 5$ could result from receptor editing in secondary lymphoid organs after induction of somatic hypermutation.

It is interesting to note that there was no overrepresentation of the single member of the Vк4 family, B3, in the nonproductive rearrangements, although this gene was clearly overrepresented in the productive repertoire of the SLE patient. The current data indicate that biased expression of B3 in this SLE patient did not result from an abnormally biased recombination process, but rather from events that occurred after recombination and were dependent on expression of $a \mathrm{k}$ chain protein. B3 is the most $\mathrm{J}_{\kappa}$ proximal gene and its overrepresentation in the productive repertoire could be the result of positive selection. However, B3 frequently was rearranged to $\mathrm{J}_{\kappa} 5$ (three out of eight times), and when it was rearranged to $\mathrm{J}_{\kappa} 5$, it contained less mutations than when it was rearranged to Jk1-4 $(2.4 \%$ vs. $3.2 \%)$. These results imply that some of the overrepresentation of B3 in the productive repertoire of this SLE patient might also result from receptor editing in secondary lymphoid organs. B3 would be available for receptor editing on the unrearranged $V_{\kappa}$ locus as well as on the same chromosome when the initial rearrangements involved $V_{\kappa}$ genes of the distal cassette known to undergo rearrangements by inversion
(27). In this latter circumstance, B3 would be retained and oriented so that it can rearrange by deletion in secondary lymphoid organs. Of importance, the B3 gene has been shown to encode for autoantibodies including the anti-dsDNA specific idiotype $\mathrm{F}^{+}{ }^{+}$(37) suggesting that receptor editing to the B3 gene may contribute to autoantibody formation in some circumstances.

It is interesting to note that $\mathrm{J}_{\kappa} 4$ genes were detected less frequently in this SLE patient, although $\mathrm{J}_{\kappa} 4$ has been reported to be frequently used for murine anti-dsDNA antibodies (38) as well as for a pathogenic 16/6 idiotypic positive human antiDNA antibody (3F7-8; 39), and other human anti-dsDNA antibodies (37) and for anti-Ro antibodies (40). In this circumstance, autoantibodies might arise despite extensive negative selection and/or receptor editing of $\mathrm{V}_{\kappa} \mathrm{J}_{\kappa}$ rearrangements including $\mathrm{J}_{\kappa} 4$. Thus, autoantibodies in SLE might arise from $\mathrm{V}_{\kappa} \mathrm{J}_{\kappa}$ rearrangements that are either incompletely deleted by receptor editing or alternatively introduced by the process of receptor editing.

Based upon the comparison with the productive $V_{\mathrm{K}}$ repertoires of the normal donors, receptor editing appeared to be greatly enhanced in this SLE patient. In transgenic animals expressing autoantibody encoding transgenes, receptor editing has been shown to rescue B cells by providing an alternative nonautoreactive $\mathrm{B}$ cell receptor, often leading to a marked skewing toward $\mathrm{J}_{\kappa} 5$ expressing $\mathrm{V}_{\kappa}$ gene products $(10,11,41$, 42). These findings have led to the conclusion that receptor editing at the $\kappa$ locus plays a major role in rescuing autoreactive $B$ cells from deletion (10). It has also been suggested that defects in receptor editing may play a role in the etiology of SLE (12-15). Contrary to this conclusion, however, the current data suggest that this rescue mechanism is intact and even exaggerated in this SLE patient, implying that defects of receptor editing do not routinely account for the emergence of autoantigen binding B cells.

The apparent exaggerated degree of receptor editing in this SLE patient has implications concerning the etiology of this autoimmune condition. The remarkable usage of receptor editing may merely reflect a more extensive degree of B cell stimulation than that found in normals. In this regard, more extensive proliferation of $\mathrm{B}$ cells with the generation of more memory B cells may predispose to increased use of $\mathrm{J}_{\kappa} 5$ in the expressed repertoire. This seems to be unlikely to explain the current findings, however, as normal memory cells defined, by the presence of mutated Vк rearrangements, show no preference for the use of $\mathrm{J} \kappa 5$ (data not shown). It is more likely that the SLE patient used receptor editing as a means to delete Ig receptors that might have developed autoantibody specificity as a result of somatic hypermutation. Since, however, the patient exhibited a number of autoantibodies despite extensive receptor editing, the data suggest that this mechanism was insufficient to prevent autoimmunity. The results therefore suggest that the drive for ongoing B cell stimulation may overwhelm the capacity of receptor editing to prevent autoimmunity.

Studies using transgenic mice have examined receptor editing in B cells with germline encoded autoreactive Ig chains (10-12, 41, 42). However, reactivation of RAG genes and recombination in the periphery (7-9) have been documented and suggest a mechanism whereby autoantibodies that arise as a result of somatic hypermutation can be edited. This mechanism appears to be robust in SLE. The results concerning the function of receptor editing of germline encoded autoantibod- 
ies in this patient are less clear. One indication that this might be intact in this SLE patient is the evidence of deletion of A30/ $\mathrm{J}_{\kappa} 2$ rearrangements that have been shown to be deleted in normals by a mechanism that may relate to receptor editing (18). Although the current study did not prove that receptor editing deleted $\mathrm{A} 30 / \mathrm{J}_{\kappa} 2$ rearrangements from the productive repertoire of this SLE patient, a previous study had suggested that this is the mechanism in normals (13). Although a previous analysis suggested that A30 might be defective and not rearranged in some SLE patients (13), the patient studied here rearranged this gene frequently and always to $\mathrm{J}_{\kappa} 2$ but deleted it normally. The retention of this deletional editing function may explain the lack of anti-dsDNA antibodies in this patient as the product of this gene is a frequent component of cationic anti-dsDNA antibodies $(13,43)$.

This study documents that receptor editing at the Vк locus is used more apparently in a patient with untreated SLE than in normals. Despite this, autoimmunity emerged. Of note, however, this patient did not express anti-ds DNA antibody. These results suggest that receptor editing in this patient was not defective but rather active, although insufficient to prevent all autoimmunity. Therefore, receptor editing is not uniformly defective in SLE, whereas other mechanisms, such as clonal deletion or anergy, may be disturbed so as to allow the emergence of autoantibody formation.

\section{Acknowledgments}

The authors are grateful to Dr. H.-P. Brezinschek for helpful discussions, Dr. R.I. Brezinschek for assistance with the cell sorting, and Dr. A.C. Grammer for critical review of the manuscript.

This work was supported by National Institutes of Health grant AI 31229. T.D. is a recipient of a Deutsche Forschungsgemeinschaft grant (Do 491/2-1).

\section{References}

1. Tan, E.M. 1989. Antinuclear antibodies: diagnostic markers for autoimmune diseases and probes for cell biology. Adv. Immunol. 44:93-151.

2. Alt, F.W., E.M. Oltz, F. Young, J. Gorman, G. Taccioli, and J. Chen. 1992. VDJ recombination. Immunology Today. 13:306-314.

3. Tonegawa, S. 1983. Somatic generation of antibody diversity. Nature. 302:575-581.

4. Nussenzweig, M.C., A.C. Shaw, E. Sinn, D.B. Danner, K.L. Holmes, H.C. Morse III, and P. Leder. 1987. Allelic exclusion in transgenic mice that express the membrane form of immunoglobuline mu. Science. 236:816-819.

5. Russell, D.M., Z. Dembic, G. Morahan, J.F. Miller, K. Burki, and D. Nemazee. 1991. Peripheral deletion of self-reactive B cells. Nature. 354:308311.

6. Tiegs, S.L., D.M. Russell, and D. Nemazee. 1993. Receptor editing in self-reactive bone marrow B cells. J. Exp. Med. 177:1009-1020.

7. Kelsoe, G. 1996. Life and death in germinal centers (Redux). Immunity. 4:107-111.

8. Han, S., S.R. Dillon, B. Zheng, M. Shimoda, M.S. Schlissel, and G. Kelsoe. 1997. V(D)J recombinase activity in a subset of germinal center B lymphocytes. Science. 278:301-305.

9. Papavasiliou, F., R. Casellas, H. Suh, X.F. Qin, E. Besmer, R. Pelanda, D. Nemazee, K. Rajewski, and M.C. Nussenzweig. 1997. V(D)J recombination in mature B cells: a mechanism for altering antibody responses. Science. 278:298302.

10. Luning Prak, E., M. Trounstine, D. Huszar, and M. Weigert. 1994. Light chain editing in $\kappa$-deficient animals: a potential mechanism of B cell tolerance. J. Exp. Med. 180:1805-1815.

11. Luning Prak, E., and M. Weigert. 1995. Light chain replacement: a new model for antibody gene rearrangement. J. Exp. Med. 182:541-548.

12. Radic, M.Z., and M. Zouali. 1996. Receptor editing, immune diversification and self-tolerance. Immunity. 5:505-511.

13. Suzuki, N., T. Harada, S. Mihara, and T. Sakane. 1996. Characterization of a germline encoding cationic anti-DNA antibody and role of receptor editing for development of the autoantibody in patients with systemic lupus erythematosus. J. Clin. Invest. 98:1843-1850.

14. Suzuki, N., S. Mihara, and T. Sakane. 1997. Development of pathogenic anti-DNA antibodies in patients with systemic lupus erythematosus. FASEB J. 11:1033-1038.

15. Bensimon, C., P. Chastagner, and M. Zouali. 1994. Human lupus antiDNA autoantibodies undergo essentially primary $\mathrm{V}$ kappa gene rearrangements. EMBO J. 13:2951-2962.

16. Manheimer-Lory, A.J., M. Irignoyen, B. Gaynor, R. Monhian, A. Splaver, and B. Diamond. 1995. Analysis of V kappa I and V lambda II light chain genes in the expressed B cell repertoire. Ann. NY Acad. Sci. 764:301-311.

17. Manheimer-Lory, A.J., R. Monhian, A. Splaver, B. Gaynor, and B. Diamond. 1995. Analysis of the V kappa I family: germline genes from an SLE patient and expressed autoantibodies. Autoimmunity. 20:259-265.

18. Foster, S.J., H.P. Brezinschek, R.I. Brezinschek, and P.E. Lipsky. 1997. Molecular mechanisms and selective influences that shape the kappa gene repertoire of IgM + B cells. J. Clin. Invest. 99:1614-1622.

19. Tan, E.M., A.S. Cohen, J.F. Fries, A.T. Masi, D.J. McShane, N.F. Rothfield, J.G. Schaller, N. Talal, R.J. Winchester. 1982. The 1982 revised criteria of systemic lupus erythematosus. Arthritis Rheum. 25:1271-1277.

20. Brezinschek, H.P., R.I. Brezinschek, and P.E. Lipsky. 1995. Analysis of the heavy chain repertoire of human peripheral B cells using single-cell polymerase chain reaction. J. Immunol. 155:190-201.

21. Brezinschek, H.P., S.J. Foster, R.I. Brezinschek, T. Dörner, R. DomiatiSaad, and P.E. Lipsky. 1997. Analysis of the human VH gene repertoire: differential effects of selection and somatic hypermutation on human peripheral $\mathrm{CD} 5+/ \mathrm{IgM}+$ and CD5-/IgM + B cells. J. Clin. Invest. 99:2488-2499.

22. Tomlinson, I.M., S.C. Williams, S.J. Corbett, J.B.L. Cox, and G. Winter. 1996. V BASE Sequence Directory. MRC Centre for Protein Engineering, Cambridge, UK

23. Dörner, T., H.P. Brezinschek, R.I. Brezinschek, S.J. Foster, R. DomiatiSaad, and P.E. Lipsky. 1997. Analysis of the frequency and pattern of somatic mutations within non-productively rearranged human $\mathrm{V}_{\mathrm{H}}$ genes. J. Immunol. 158:2779-2789.

24. Dörner, T., H.P. Brezinschek, S.J. Foster, R.I. Brezinschek, N.L. Farner, and P.E. Lipsky. 1998. Delineation of selective influences shaping the mutated expressed human immunglobulin heavy chain repertoire. J. Immunol. 160: 2831-2841.

25. Dörner, T., H.P. Brezinschek, S.J. Foster, R.I. Brezinschek, N.L. Farner, and P.E. Lipsky. 1998. Comparable impact of mutational and selective influences in shaping the expressed repertoire of peripheral $\mathrm{IgM}+/ \mathrm{CD} 5-$ and IgM+/CD5+ B cells. Eur. J. Immunol. 28:657-668.

26. Woolson, R.F. 1987. Statistical Methods for the Analysis of Biomedical Data. John Wiley \& Sons, New York. 337 pp.

27. Schable, K.F., and H.G. Zachau. 1993. The variable genes of the human immunoglobulin к locus. Biol. Chem. (Hoppe-Seyler). 374:1001-1022.

28. Ray, S.K., C. Putterman, and B. Diamond. 1996. Pathogenic autoantibodies are routinely generated during the response to foreign antigens: a paradigm for autoimmune disease. Proc. Natl. Acad. Sci. USA. 93:2019.

29. vanEs, J.H., F.H.J. Gmelig-Meyling, W.R.M. van de Akker, H. Aanstoot, R.H.W.M. Derksen, and T. Logtenberg. 1991. Somatic mutations in the variable regions of human $\mathrm{IgG}$ anti-double stranded DNA antibodies suggest a role for antigen in the induction of SLE. J. Exp. Med. 173:461.

30. Shlomchik, M., M. Mascelli, H. Shan, M.Z. Radic, D. Pisetsky, A. Marshak-Rothstein, and M. Weigert. 1990. Anti-DNA antibodies from autoimmune mice arise by clonal expansion and somatic mutation. J. Exp. Med. 171: 265.

31. Diamond, B., and M.D. Scharff. 1984. Somatic mutation of the T15 heavy chain gives rise to an antibody with autoantibody specificity. Proc. Natl. Acad. Sci. USA. 81:5841-5844.

32. Shlomchik, M.J., A. Marshak-Rothstein, C.B. Wolfowicz, T.L. Rothstein, and M.G. Weigert. 1987. The role of clonal selection and somatic mutation in autoimmunity. Nature. 328:805-811.

33. Roben, P., S.M. Barbas, L. Sandoval, J.M. Lecerf, B.D. Stollar, A. Solomon, and G.J. Silverman. 1996. Repertoire cloning of lupus anti-DNA autoantibodies. J. Clin. Invest. 98:2827-2837.

34. Radic, M.Z., and M. Weigert. 1995. Origins of anti-DNA antibodies and their implications for B-cell tolerance. Ann. NY Acad. Sci. 764:384-396.

35. Ibrahim, S.M., M. Weigert, C. Basu, J. Erikson, and M.Z. Radic. 1995. Light chain contribution to specificity in anti-DNA antibodies. J. Immunol. 155: 3223-3233.

36. Schwartz, R.S., and B.D. Stollar. 1994. Heavy-chain directed B-cell maturation: continous clonal selection beginning at the pre-B cell stage. Immunol. Today. 15:27-32.

37. Manheimer-Lory, A.J., G. Zandman-Goddard, A. Davidson, C. Aranow, and B. Diamond. 1997. Lupus-specific antibodies reveal an altered pattern of somatic mutation. J. Clin. Invest. 100:2538-2546.

38. Swanson, P.C., R.L. Yung, N.B. Blatt, M.A. Eagan, J.M. Norris, B.C. Richardson, K.J. Johnson, and G.D. Glick. 1996. Ligand recognition by murine anti-DNA autoantibodies. J. Clin. Invest. 97:1748-1760.

39. Waisman, A., P.J. Ruiz, and E. Mozes. 1996. Variable regions of two 
murine antibodies that bind the SLE associated 16/6 idiotype. Lupus. 5:279286.

40. Suzuki, H., H. Takemura, M. Suzuki, Y. Sekine, and H. Kashiwagi. 1997. Molecular cloning of anti-SS-A/Ro $60 \mathrm{kDa}$ peptide Fab fragments from infiltrating salivary gland lymphocytes of a patient with Sjögren's syndrome. Biochem. Biophys. Res. Commun. 232:101-106.

41. Chen, C., E. Luning-Prak, and M. Weigert. 1997. Editing disease-associated autoantibodies. Immunity. 6:97-105.
42. Gay, D., T. Saunders, S. Camper, and M. Weigert. 1993. Receptor editing: an approach by autoreactive B cells to escape tolerance. J. Exp. Med. 177: 999-1008.

43. Harada, T., N. Suzuki, Y. Mizushima, and T. Sakane. 1994. Usage of a novel class of germline immunoglobulin variable region gene for cationic antiDNA autoantibodies in human lupus nephritis and its role for the development of the disease. J. Immunol. 1153:4806-4815. 